\title{
Low Osmolarity Oral Rehydration Salt Solution (LORS) in Management of Dehydration in Children
}

\author{
Nimain Mohanty ${ }^{1}$, Babu Ram ThaPa $^{2}$, John Mathai ${ }^{3}$, Uday PaI $^{4}$, NiRANJan Mohanty $^{5}$, Vishnu Biradar $^{6}$, \\ Pramod Jog ${ }^{7}$ and Purnima Prabhu ${ }^{8}$ \\ ${ }^{1}$ Department of Pediatrics, MGM Institute of Health Sciences, Navi Mumbai, Maharashtra, India; ${ }^{2}$ Department of Gastroenterology, \\ Liver and Nutrition, PGIMER, Chandigarh, India; ${ }^{3}$ Consultant in Pediatric GE, Masonic Children 's Hospital, Coimbatore, India; \\ ${ }^{4}$ Consultant Pediatrician, Chembur, Mumbai, India; ${ }^{5}$ Department of Pediatrics, KIMS, Bhubaneswar, Odisha, India; ${ }^{6}$ Department \\ of Pediatrics, Deenanath Mangeshkar Hospital and Research Centre, Pune, Maharashtra, India; ${ }^{7}$ Department of Pediatrics, DY \\ Patil Medical College, Pune, Maharashtra, India, ${ }^{8}$ Pediatric Nutritionist, P.D. Hinduja Hospital, Mumbai, Maharashtra, India. \\ Correspondence to: Prof. Nimain Mohanty, Department of Paediatrics, MGM Medical College, Kamothe, Navi Mumbai 410209 , \\ Maharashtra, India.nimain.mohanty@gmail.com
}

Justification: The IAP last published the guidelines "Comprehensive Management of Diarrhea" in 2006 and a review in 2016. The WHO in 2002 and the Government of India in 2004 recommended low osmolarity rehydration solution (LORS) as the universal rehydration solution for all ages and all forms of dehydration. However, the use of LORS in India continues to be unacceptably low at $51 \%$, although awareness about ORS has increased from a mere $14 \%$ in 2005 to $69 \%$ in 2015 . Availability of different compositions of ORS and brands in market added to the confusion. Process: The Indian Academy of Pediatrics constituted a panel of experts from the fields of pediatrics, pediatric gastroenterology and nutrition to update on management of dehydration in children with particular reference to LORS and issue a current practice guideline. The committee met twice at CIAP HQ to review all published literature on the aspect. Brief presentations were made, followed by discussions. The draft paper was circulated by email. All relevant inputs and suggestions were incorporated to arrive at a consensus on this practice guideline. Objectives: To summarize latest literature on ORT and empower pediatricians, particularly those practicing in rural areas, on management of dehydration by augmenting LORS use. Recommendations: It was stressed that advantages of LORS far out-weigh its limitations. Increased use of LORS can only be achieved by promoting better awareness among public and health-care providers across all systems of medicine. LORS can also be useful in managing dehydration in non-diarrheal illness. More research is required to modify ORS further to make it safe and effective in neonates, severe acute malnutrition, renal failure, cardiac and other co-morbidities. There is an urgent need to discourage production and marketing all forms of ORS not in conformity with WHO approved LORS, under a slogan "One India, one ORS".

Keywords: Diarrhea, Management, Oral rehydration therapy.

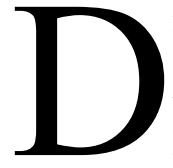
iarrhea is the second leading cause of death after pneumonia among children below 5 years of age in India [1,2]. The 4th National Family Health Survey reported that $9.2 \%$ of under- 5 children had diarrhea during the preceeding two weeks [3]. The situation remained same even after a decade, as the incidence was 9\% in 2005 [4] Death in diarrhea is mainly from dehydration and its complications. Therefore, appropriate rehydration therapy remains the cornerstone in management. Advances in molecular technology have helped to better understand the etiology and pathophysiology of diarrhea. It helped conceptualizing and improving oral rehydration therapy.

WHO launched global diarrheal diseases control program with oral rehydration therpay (ORT) as its core strategy in year 1978 [5]. Being concerned with hypernatremia, especially in children having non-cholera diarrhea, single low osmolar ORS (LORS) formulation was recommended as an universal solution by WHO and UNICEF in a joint statement in which LORS was recommended as safe and effective to correct dehydration in diarrhea, including cholera in adults as well as children [6]. The Government of India followed the lead and approved the same composition of LORS as a single rehydration solution.

Multi-centric studies in India and Bangladesh established safety and efficacy of LORS in non-cholera as well as cholera related diarrhea without significant symptomatic hyponatremia [7]. The European Society for Pediatric Gastroenterology and Nutrition (ESPGHAN) as well as the North Americal Society for Pediatric Gastroenterology and Nutrition (NASPGHAN) committee also endorsed safety and efficacy of LORS for use in diarrhea [8].

\section{BACKGROUND}

Mechanisms of diarrhea: There are four main mechanisms. Secretory diarrhea: Toxin induced active out-put of fluid into small intestine as in cholera and entero-toxogenic E. Coli (ETEC). It can result in severe 
dehydration, metabolic acidosis and dyselectrolytemia due to rapid loss of fluid, bicarbonate and electrolytes, especially potassium [9].

Osmotic diarrhea: Mucosal damage leads to unabsorbed substances, mainly carbohydrates in small intestine. It results in high osmotic load and consequent passive movement of fluid and electrolytes into the lumen. An example is rotavirus-induced temporary lactose intolerance. Other etiological agents include norovirus, astrovirus and enteroviruses.

Bloody diarrhea: Diarrhea with visible blood in the stool is called dysentery and is associated with systemic symptoms like fever and crampy abdominal pain. Common infective causes include Shigella, Salmonella, enteroinvasive E.coli and Entamoeba histolytica, while non-infective causes include inflammatory bowel disease and milk protein allergy. The large bowel is predominantly involved and usually it does not cause dehydration.

Malabsorptive diarrhea: The classic examples are diffuse mucosal disease, defects in pancreas and/or biliary system, celiac disease, giardiasis and cystic fibrosis. There is defective digestion or absorption of nutrients, minerals and vitamins, resulting in malnutrition or failure to thrive. Dehydration and electrolyte imbalance are seen only in prolonged and severe disease.

Watery diarrhea: It typically emanates from small bowel, either by abnormal secretory or osmotic process. Concentration of electrolytes in luminal contents remains in a state of equilibrium with that of blood. Any change in this bi-directional flow, either by increased secretion or decreased absorption or both, result in excess fluid entering large intestine. Diarrhea results if the fluid exceeds maximal absorptive capacity of colon [10].

Basis for shifting to low-osmolar ORS (LORS): With improved infrastructure, water supply and better sanitation, incidence of cholera decreased considerably over time. On the other hand, Rotavirus diarrhea was recognized as a major etiological agent for acute diarrhea in children.
Significantly lower stool electrolyte losses $\left(\mathrm{Na}^{+}, \mathrm{K}^{+}\right.$, bicarbonate) in non-cholera diarrhea was recognized. Of particular concern was that sodium loss in rotavirus diarrhea was much less $(52 \mathrm{mmol} / \mathrm{L})$ than in cholera $(90$ $\mathrm{mmol} / \mathrm{L})$, resulting in a much higher incidence of hypernatremia with conventional ORS $[9,10]$. The earlier WHO ORS had poor acceptance by mothers for not reducing incidence of vomiting and stool volume [11]. LORS, having lower osmolarity (245 $\mathrm{mOsm} / \mathrm{L})$ than plasma (290 mMol/L), facilitated absorption of sodium and water faster (Table I). Active absorption of glucose and amino acids was promoted. Not only LORS replaced fluid and electrolytes faster, it also decreased luminal volume by quick absorption, thus reducing chance of vomiting and stool volume across all ages. It also helped in reducing the need for unscheduled supplemental intravenous therapy [6] There were initial hesitation and resistance to change despite recommendations from the American Academy of Pediatrics (AAP), WHO, ESPGHAN and NASPGHAN to use LORS by parents and caregivers but the acceptance improved fast $[12,13]$.

\section{PROCESS}

The Indian Academy of Pediatrics constituted a panel of experts from the field of general pediatrics, pediatric gastroenterology and nutrition to update on management of diarrhea in children with particular reference to LORS. The committee met on August 5, 2018 and on June 23, 2019 in Mumbai, and reviewed all published literature and reports of expert bodies on the relevant aspects on managing dehydration with ORS. Brief presentations were made and followed by discussions. A draft practice guideline was compiled and circulated by email to all members. Several useful inputs were received which were incorporated to arrive at a consensus document. Finally the guideline was placed before the IAP Executive Body Meeting, 2020 which was approved.

\section{RECOMMENDATIONS}

\section{Rehydration in Watery Diarrhea}

Current management practice in diarrhea follows WHO

Table I Electrolyte Composition of Plasma, Stool and Oral Rehydration Solution (ORS) [6,11]

\begin{tabular}{|c|c|c|c|c|c|c|c|}
\hline \multirow[b]{2}{*}{ Composition } & \multicolumn{7}{|c|}{ Composition $(\mathrm{mMol} / \mathrm{L})$} \\
\hline & $\mathrm{Na}$ & $K$ & $\mathrm{Cl}$ & $\mathrm{HCO}_{3}$ & Citrate & Glucose & Osmolarity \\
\hline Human plasma & 135 & 5 & - & 25 & - & 90 & 290 \\
\hline Cholera stool & 105 & 25 & 30 & 30 & - & - & - \\
\hline Non-cholera stool & 52 & 25 & 14 & 14 & - & - & - \\
\hline Conventional ORS & 90 & 20 & 80 & - & 10 & 111 & 311 \\
\hline Low osmolar ORS & 75 & 20 & 65 & - & 10 & 75 & 245 \\
\hline ReSoMal & 45 & 40 & 76 & - & 7 & 125 & 300 \\
\hline
\end{tabular}




\section{Key Recommendations}

Strategies Need to be Operationalized Nation-wide for Increasing LORS Use

- Ensuring uniform composition of ORS in market for Sachet and readymade solutions, with legally binding regulatory guidelines. Popularise the slogan, 'One country - one ORS.'

- Declaring LORS as a lifesaving drug

- Making LORS freely available at anganwadis, schools, kirana stores and pharmacies in moisture proof foil packs, clearly specifying that it confirms to WHO composition [35].

- Diarrhea management and use of ORS may be included in the school curriculum.

- Celebrating IDCF week in all education institutes and primary health-care facilities ass a mass movement like Pulse Polio Program.

- Persuading industries to take up diarrhea management, manufacturing, distributing and popularising LORS as their corporate social responsibility (CSR).

- Conducting education programs, refresher courses and workshops to improve and reinforce knowledge of basic health workers as well as practitioners from all systems of medicine.

- Provision for safe and wholesome drinking water at all nook and corner of the country [36].

- Social and electronic media be pressed into action to educate the public on ORS, particularly in the rural areas, with catchy slogans beaming and programs in local language by eminent personalities as brand ambassadors.

- Co-ordinated effort by public-private partnership while mitigating private sector risks for achieving public sector objectives in popularising and making ORS freely available.

- Evolving innovative strategies by experts for key behaviour change among stake holders to establish credibility of LORS for prevention and management of dehydration.

[6] and ESPGHAN [8] guidelines, focusing on oral rehydration therapy, continued feeding and zinc supplementation. WHO outlined treatment of dehydration in diarrhea according to grades of dehydration such as 'No dehydration', 'Some dehydration' and 'Severe dehydration' on specific clinical symptoms and signs $[14,15]$. Certain clinical signs are considered more specific and dependable. Of the ten commonly used signs to assess dehydration, prolonged capillary refill time, abnormal skin turgor, abnormal respiratory pattern, cool extremities, weak pulse and absence of tear have higher specificity [16] Management plan- $\mathrm{A}$ is the home management of diarrhea with very mild or no dehydration. LORS is advised at the rate of $10 \mathrm{~mL} / \mathrm{kg}$ with each episode of watery stool. Breastfeeding is advised more frequently and for longer duration at each feed, if exclusively breastfeed. If not exclusively breastfed, food-based fluids such as soup, rice water or rice gruel, coconut water, yogurt and clean water offered frequently, apart from LORS. If on complementary feed, must continue what child had been taking from family pot. Plan-B is for mild to moderate dehydration or some dehydration. LORS is given as 50 to $100 \mathrm{~mL} / \mathrm{kg}$ of bodyweight (Average $75 \mathrm{~mL} / \mathrm{kg}$ ) at the day care center or ORS corner over 3 to 4 hours; $12-25 \mathrm{~mL} / \mathrm{kg}$ in the first hour in sips from cup and spoon, under supervision. To start with, $1-2 \mathrm{~mL} / \mathrm{kg}$ may be given every 5 minutes to prevent vomiting and increased gradually as the child accepts more. In the event of vomiting, ORS is withheld for 15 to 30 minutes and then resumed. Current clinical condition, on-going loss and renal status are taken into account for fluid replacement within 4 to 6 hours, albeit at a slower rate in infants (Half of replacement fluid in first one hour for infants and in 30 minutes for children). Reassessment of hydration is done every four hours. Once dehydration is corrected, plan A management to continue. Mother is always counselled about red flag signs and when to return immediately.

LORS for children with cholera: LORS has been found to be safe and effective in correcting dehydration in a subgroup of $9 \%$ patients who were diagnosed as cultureproven cholera [7]. A systemic review by WHO on several studies conducted in children with cholera treated either with LORS or standard WHO ORS, reaffirmed the safety and efficacy of LORS. The mean serum sodium in children with cholera was found slightly lower after 24 hours (mean $131 \mathrm{mEq} / \mathrm{L}$ ) than those having non-cholera diarrhea (mean $137 \mathrm{mEq} / \mathrm{L}$ ), both being within acceptable range [6].

Vomiting: If the child is vomiting repeatedly, thorough clinical examination is warranted to rule out any organic or metabolic cause needing urgent intervention. Cases of recurrent vomiting, severe dehydration, dyselectrolytemia or sepsis should be hospitalized for investigations, intravenous fluid, close monitoring and early intervention. With persistent vomiting and/or increasing abdominal distension, sips of LORS can be given slowly, checking bowel sounds. Vomiting by itself is a cause of dehydration, worsening fluid loss as well as impairing oral rehydration. Oral ondansetron is considered safer for 
children to arrest vomiting with $0.15 \mathrm{mg} / \mathrm{kg} / \mathrm{dose}$ on as and when basis $[17,18]$. Usual feeding must continue which helps early mucosal repair and prevent malnutrition [8,14]. Administering zinc in diarrhea for two weeks, particularly in south-east Asia region where the soil is zinc deficient and people are mostly vegetarian, is recommended, although debated recently $[19,20]$.

\section{LORS for Special Situations}

\section{Severe Acute Malnutrition (SAM)}

Malnutrition is an underlying risk factor for diarrhea, causing of $61 \%$ of child deaths globally [1]. Diarrhea in children with SAM carries an 8-9 times higher mortality [2]. With improved access to better health care, deaths from diarrhea in hospitalized children now occurs only if malnutrition is co-existing. Decreased food intake, loss of appetite, poor absorption and increased nutrient requirement - all result in weight loss and delayed recovery from diarrhea, creating a vicious cycle. In these children, dehydration should not only be corrected quickly and nutritional rehabilitation should be simultaneously started with F-75 feeding [21]. There are additional risks of fluid retention, hypernatremia and cardiac failure if higher sodium containing fluids are used for rehydration. WHO recommends ReSoMal with low sodium for such children [22]. The Indian Academy of Pediatrics in 2006 suggested a modified rehydration fluid (mReSoMal) to provide $\mathrm{Na}^{+} 45 \mathrm{mMol} / \mathrm{L}, \mathrm{K}^{+} 40 \mathrm{mMol} / \mathrm{L}$, zinc, copper and magnesium [23]. Results of multicentric studies by Alam, et al. [24] compared low $\mathrm{Na}^{+}$ mRESoMal with standard WHO LORS in 130 children of 6 to 36 months age having acute diarrhea on SAM. 29\% of subjects in mReSoMal group were found to be having hyponatremia in at 48 hours. Out of them, three had severe hyponatremia. On the other hand, only $10 \%$ developed hyponatremia in LORS group. Over hydration was reported in 5\% and $12 \%$ of mReSoMal and LORS groups respectively [24]. In yet another RCT with 104 children, Kumar, et al. [25] used one sachet of LORS, 40 grams of sugar and $35 \mathrm{ml}$ of potassium chloride solution added to $1700 \mathrm{ml}$ of water to nearly match mReSoMal. Their other arm used LORS in one liter of water to which $15 \mathrm{ml}$ of potassium chloride was added to take care of hypokalemia, commonly seen in SAM. Both types of fluid were found effective in correcting dehydration and hypokalemia, but the mReSoMal group took comparatively lesser time for correction and also had lesser incidence of hypernatremia [25]. Further, a systematic review of six RCTs, conducted in low resource settings in Asia, showed that LORS therapy took lesser time to rehydrate; with decreased stool volume and duration of diarrhea. None reported over-hydration or serious fatalities due to hyponatremia. WHO guidelines strongly recommend using ReSoMal universally but not supported by high quality evidence as certain RCTs shown an increased risk of hyponatraemia with WHO ReSoMal in Asian children. Therefore, more studies, especially from Africa were felt necessary [26]. Considering available data, either LORS dissolved in one litre of water with $15 \mathrm{~mL}$ of $20 \%$ Potassium chloride solution, or mReSoMal can be considered effective for rehydration as well as correcting basal hypokalemia associated in SAM with diarrhea.

\section{Neonates and Infants}

Larger body surface area to body mass ratio result in higher insensible water loss, besides immature kidneys. They are prone to asymptomatic hypernatremia with narrow safety window in intravascular vis-a-vis extravascular compartment. They quickly slip into severe dehydration and related complications. LORS can be administered above 2 months under supervision, while continuing breastfeeding [14]. There is insufficient evidence to recommend ORS below that age.

\section{Severe Dehydration, Where Facility for Intravenous Fluid Therapy Is Not Available}

In resource limited settings where IV treatment facility is either not feasible or it is not possible to access IV line due to edema or collapsed veins, sips of LORS or through $\mathrm{NG}$ tube at the rate of $20 \mathrm{~mL} / \mathrm{kg}$ per hour for 6 hours (total $120 \mathrm{~mL} / \mathrm{kg}$ ) may be initiated. Reassessment every 1-2 hours is essential. Once the collapsed veins stand out, IV lines can easily be established. Enteral fluid therapy for 24 hours as compared to rapid IV fluid of $40-50 \mathrm{~mL} / \mathrm{kg}$ in 4 to 6 hours found equally effective. Far less adverse events and shorter hospital stay are advantages [8].

\section{Renal Failure}

Azotemia occurs secondary to poor renal perfusion or acute tubular necrosis. A good amount of bicarbonate is lost in diarrheal which normally gets replenished by kidneys. Acidosis occurs due to base deficit and excess lactic acid production. Severe metabolic acidosis results in increased vomiting, deep but rapid breathing and altered sensorium. Enteral feeding with LORS in calculated amount under supervision can be considerd enroute to referral centre, pending intravenous fluid and appropriate corrections after assessing renal status $[14,15]$.

\section{Acute Febrile IIIness}

Fever often cause excessive fluid loss due to increased sweating, diminished thirst and poor water intake adversely impacting water-electrolyte balance. An 
Table II LORS Use Rates in Diarrhea Found in National Family Health Surveys (NFHS)-4 [3,4]

\begin{tabular}{llllr}
\hline Parameters related to Diarrhea & \multicolumn{2}{c}{ NFHS-4(2015-16) } & NFHS-3 (2005-06) \\
\cline { 2 - 4 } & Urban & Rural & Overall & 9.0 \\
\hline Prevalence in 2 week preceding survey & 8.2 & 9.6 & 9.2 & 26.0 \\
Cases in last 2 week who received ORS, \% & 58.5 & 47.9 & 50.6 & - \\
Cases in last 2 week who received zinc, \% & 23.7 & 19.1 & 20.3 & 61.3 \\
Cases in last 2 week taken to health facility, \% & 74.1 & 65.8 & 67.9 & \\
\hline
\end{tabular}

additional $20 \%$ fluid intake is advised in all cases of fever irrespective of the cause. Fever is often associated with vomiting, particularly in small children. It can cause dehydration and electrolyte imbalance, warranting intravenous fluids and hospitalization. Early administration of LORS can prevent such eventualities [27].

Dengue and other viral infections: LORS is preferred for treatment of mild to moderate dehydration, rather than plain water in febrile dengue patients. Fruit juice or any other home based fluids, and ORS are encouraged, while continuing feeding [28]. Other viral infections, including Ebola and COVID-19 during fever cause dehydration and demand sufficient fluids, including ORS.

Typhoid: Dehydration is common in high fever, vomiting, poor feeding, loose stool, hepatitis and so on. Hypoglycemia, hypokalemia and hyponatremia occur frequently and oral or intravenous hydration are essential. LORS, home based fluids and appropriate diet are considered vital [29].

Malaria: A significant association was found between severity of dehydration and parasitemia. Prevalence of malaria-associated diarrhea was found in $61.7 \%$ of cases in Ghana. Parasite-positivity was associated with high fever and vomiting, causing dehydration. ORS was found invaluable in preventing dehydration and hypoglycemia [30].

Heat stroke: It results in refractory and prolonged hyperpyrexia (Core body temperature $>41^{\circ} \mathrm{C}$ ), dehydration and dyselectrolytemia. Cool bath, sponging, ice packs, spraying cold water are important in management. In a Japanese study on 153 adult loaders at an airport cargo terminal in summer with $30^{\circ} \mathrm{C}$, the subjects were either given conventional ORS ( $\mathrm{Na} 90 \mathrm{mMol} / \mathrm{L})$ or their favorite beverages (Tea or coffee) on different days. Their fatigue score was found significantly lower on ORS intake days than on beverages days. The results suggested that intake of ORS during outdoor work in the hot environment can effectively prevent accidents and heat stroke [31]. These recommen-dations can safely be extrapolated, recommending LORS use in children.

\section{ORS Use in the Community}

Diarrhea alleviation through zinc and ORS therapy (DAZT): This study was undertaken to understand ORS coverage to achieve reductions in diarrhea mortality, an operation research in three districts each of UP and Gujarat during 2010-14. Prescription trend in diarrhea, knowledge and practice of zinc therapy and ORS use by health care providers and family members were assessed. Structured, pre-validated questionnaires were administered to 127 healthcare providers and 43 home based care givers. Besides, 228 prescriptions from government health facilities were also analysed. It was found that Government functionaries dispensed ORS to the tune of $97 \%$ and zinc in $90 \%$ cases of diarrhea vs $79 \%$ and $71 \%$ respectively in the private sector [35].

National Family Health Surveys (NFHS): The data show that ORS use in diarrhea increased from $14 \%$ in 2005 to $26 \%$ in 2010 and to $50 \%$ in 2015 . Although the awareness and ORS access rate, a key to any diarrhea control program in community has improved over the last forty years, its actual utilization remains far below expected level $[3,4]$ (Table II). The disparity may be attributed to continued lack of public awareness, poor prescription rates of LORS, lack of perception on benefit by stake holders and practitioners. Besides, inadequate resource allocation, poor infrastructure and a general complacency are important factors.

Table III Beverages Available in Market That are Unsuitable in Diarrhea

\begin{tabular}{|c|c|c|c|c|c|c|}
\hline Products & $\begin{array}{l}\mathrm{CHO} \\
(\mathrm{mmol} / \mathrm{L})\end{array}$ & $\begin{array}{l}\text { Sodium } \\
(\mathrm{mmol} / \mathrm{L})\end{array}$ & $\begin{array}{l}\text { Potassium } \\
(\mathrm{mmol} / \mathrm{L})\end{array}$ & $\begin{array}{l}\text { Chloride } \\
(\mathrm{mmol} / \mathrm{L})\end{array}$ & $\begin{array}{l}\text { Base } \\
(\mathrm{mmol} / \mathrm{L})\end{array}$ & $\begin{array}{r}\text { Osmolarity } \\
(\operatorname{mos} M / L)\end{array}$ \\
\hline Fruit juice & 120 & 0.4 & 44 & 45 & - & 730 \\
\hline Soft drinks & 112 & 1.6 & - & - & 13.4 & 650 \\
\hline Sports/power drinks & 58.3 & 20 & 3.2 & 11 & - & 299 \\
\hline
\end{tabular}




\section{Box I Suggested Research Priorities}

- Improve calorie content and palatability of LORS without increasing osmolality,

- Address safety concerns in neonates and young infants,

- Search for a better formulation of ORS in presence of severe acute malnutrition.

The Intensified diarrhea control fortnight (IDCF): This program was launched in 2014 from 28 July to 03 August every year under the Ministry of Health and Family Welfare under Government of India, with the goal to reduce U-5 childhood mortality further. It immensely helped in creating awareness on diarrheal disease and its treatment all over the country by involving all stakeholders from doctors to grassroot workers like ASHA and Anganwadi workers. Participation of NGOs, medical colleges, primary health centers, and professional bodies of pediatricians, dieticians and nurses ensured wide publicity for the program and its successful implementation.

Barriers: There are several reasons for low use of LORS, despite massive efforts by government and NGOs over years $[33,34]$. Lack of awareness among public and basic health workers at grass root level, coupled with nonavailability of LORS in community are responsible [3]. Often pharmacies do not stock ORS for low profit margin. Many branded formulations are marketed in name of ORS do not conform to WHO composition [35]. These non-physiologic fluids have either low sodium content or high osmolarity, actually worsening diarrhea (Table III). Moreover, LORS is mostly available in powder form while ORS substitutes in market are in attractive liquid ready to drink packs, tablets and drops [35]. There is no regulatory mechanism insisting on a single, standard form of LORS sachets throughout the country. Palatability of ORS is poor owing to its citrate content, which however is vital for maintaining the $\mathrm{pH}$. This taste factor forces parents to look for alternatives. Parents do insist on intravenous fluids without justifiable indication, expecting early cure but the hospitals do little to refuse such demand on commercial considerations.

\section{CONCLUSION}

Reduced osmolarity ORS is adequate to manage dehydration in most children. Current use of ORS in diarrhea, as seen in last NFHS-4 is low, although awareness is considerably high. There are issues with use of LORS in severe acute malnutrition, for newborns and young infants, renal dysfunction. There exists scope for enteral feeding of LORS, where facilities for parenteral therapy not available or not possible. Not only diarrhea,
LORS should be popularized as an effective remedy to combat dehydration due to any cause. Steps are urgently required to ensure availability and use of only the standard WHO LORS all over the country. Appropriate research priorities have been outlined.

Funding: None; Competing interests: None stated

\section{REFERENCES}

1. Bern C, Martines J, Zoysa I de, Glass RI. The magnitude of global problem of diarrheal disease: A ten year update. Bulletin of the World Health Organization. 1992;70:705-14.

2. Global Burden of Diseases (GDB) 2016. Diarrheal disease collaborators. Estimates of the global, regional, and national morbidity, mortality and aetiologies of diarrhea in 195 countries: A systematic analysis for global burden of disease Study 2016. Lancet Infect Dis. 2018;18:1211-28.

3. International Institute for Population Sciences (IIPS) and ICF. 2017. National Family Health Survey-4, 2015-16:56-9. India. IIPS. Available from: http://www.rchiips.org/nfhs/NFHS-4Reports/ India.pdf

4. International Institute for Population Sciences (IIPS) and Macro International. 2007. National Family Health Survey (NFHS-3), 2005-06: India: Volume I. IIPS. Available from: http:// www.rchiips.org/nfhs/NFHS-3Reports/India.pdf

5. Bhattacharya SK. History of development of oral rehydration therapy. Indian J Public Health. 1994;38:39-43.

6. World Health Organisation (WHO), United Nations Children Fund (UNICEF) Joint Statement: Clinical management of acute diarrhea. WHO 2004. Available from: https://www.who.int / maternal_child_adolescent/documents/who_fch_cah_04_7/en/. Accessed June 20, 2020.

7. Alam NH, Yunus M, Abu S, et al. Symptomatic hyponatremia during treatment of dehydrating diarrheal disease with reduced osmolarity oral rehydration solution. JAMA. 2006;296:567-73.

8. Guarino A, Ashkenazi S, Gendrel D, Lo A, Shamir R, Szajewska H. European Society for Paediatric Gastroenterology, Hepatology and Nutrition/European Society for Paediatric Infectious Diseases. Evidence-Based Guidelines for the Management of Acute Gastroenteritis in Children in Europe. J Pediatr Gastroenterol Nutr.2014;59: 132-52.

9. Operario DJ, Houpt E. Etiology of diarrhea: Novel approaches. Curr Opin Inf Dis. 2011;24:464-71.

10. Hodges K, Gill R. Infectious diarrhea: Cellular and molecular mechanisms. Gut Microbes. 2010;1:4-21.

11. Hirschhorn N, Nalin DR, Cash RA, Greenough WB 3rd. Formulation of oral rehydration solution. Lancet. 2002;360:340-341.

12. Nalin DR, Cash RA. 50 years of oral rehydration therapy: Solution still simple. Lancet. 2018;392:536-8.

13. Patwari AK. Management of diarrhea - Changing trends in last 50 years. Indian Pediatr. 2018;55:63-5.

14. IMNCI Distant Learning Course. Module 4. Diarrhea. 2014; updated guidelines 2017. World Health Organisation Press, Geneva, 2017. Accessed June 20, 2020. Available from: https:// www.who.int/maternal_child_adolescent/documents/97892415 06823/en/

15. Suh JS, Hahn WH, Cho BS. Recent advances of oral rehydration therapy (ORT). Electrolyte Blood Press. 2010;8:82-6.

16. Falszewska A, Szajewska H, Dziechciarz P. Diagnostic accuracy of three clinical dehydration scales: A systematic review. Arch Dis Child. 2018;103:383-8.

17. Fedorwicz Z, Jagannath VA, Carter B. Antiemetics for reducing vomiting related to acute gastroenteritis in children and adolescents. Cochrane Database Syst Rev. 2011:CD005506.

18. Ryes JA, Veroniki AA, Florez ID. Antiemetics in children with 
acute gastroenteritis: A meta-analysis. Pediatrics. 2020;145: e20193260.

19. Walker CL, Black RE. Zinc for the treatment of diarrhea: Effect on diarrhea morbidity, mortality and incidence of future episodes. Int J Epidemiol. 2010;39:i63-i69.

20. Lazzerini M, Wanzira $H$. Oral zinc for treating diarrhea in children. Cochrane Database Syst Rev. 2016;12:CD005436.

21. Ashworth A, Khanum S, Jackson A, Schofield C. Guidelines for inpatient treatment of Severe Acute Malnurished Children. WHO, Geneva 2003. Accessed June 20, 2020. Available from: https:// www.who.int/bulletin/volumes/94/9/15-162867/en/

22. WHO. Guideline: Updates on Management of Severe Acute Malnutrition in Infants and Children. Geneva: World Health Organization: 2013. Accessed June 20, 2020. Available from: https://www. who.int/publications/i/item/9789241506328

23. Bhatnagar S, Lodha R, Choudhury P, et al. IAP guidelines 2006 on Hospital Based Management of Severely Malnourished Children (adapted from WHO Guidelines). Indian Pediatr. 2007;44:443-61.

24. Alam NH, Hamadani JD, Dewan N, Fuchs GJ. Efficacy and safety of a modified oral rehydration solution (ReSoMaL) in the treatment of severely malnourished children with watery diarrhea. J Pediatr. 2003;143:614-9.

25. Kumar R, Kumar P, Aneja S, Kumar V, Rehan HS. Safety and efficacy of low-osmolarity ORS vs. modified rehydration solution for malnourished children for treatment of children with severe acute malnutrition and diarrhea: A randomized controlled trial. J Trop Pediatr. 2015;61:435-41.

26. Houston KA, Gibb JG, Maitland K. Oral rehydration of malnourished children with diarrhea and dehydration: A systematic review. Wellcome Open Research. 2017;2:66.

27. Barbi E, Marzuillo P, Neri E. Fever in children: Pearls and pitfalls.
Children (Basel). 2017; 4:81.

28. Government of India. National Guidelines for Clinical Management of Dengue. 2015. Accessed June 20, 2020. Available from: http://pbhealth.gov.in/dengue national guidelines 2014.pdf

29. Cruz Espinoza LM, McCreedy E, Holm M, et al. Occurrence of typhoid fever complications and their relation to duration of illness preceding hospitalization: A systematic literature review and metaanalysis. Clin Infect Dis. 2019;69:S435-S448.

30. Ibadin OM, Airauhi L, Omoigberale AI, Abiodun PO. Association of malarial parasitaemia with dehydrating diarrhea in Nigerian children. J Health Popul Nutr. 2000;18:115-8.

31. Ishikawa $\mathrm{T}$, Tamura H, Ishiguro H, Yamaguchi K, Minami K. Effect of oral rehydration solution on fatigue during outdoor work in a hot environment: a randomized crossover study. J Occup Health. 2010;52:209-15.

32. LeFevre AE, Mohan D, Mazumder S, et al. Diarrhea no more: Does zinc help the poor? Evidence on the effectiveness of programmatic efforts to reach poorest in delivering zinc and ORS at scale in UP and Gujarat, India. J Glob Health. 2016;6: 021001.

33. Lanters LM, Das JK, Bhutta ZA. Systemic review of strategies to increase ORS use at household level. BMC Public Health WHO. 2013;13:S28.

34. Santosham M, Chandran A, Fitzwater S, Fischer-Walker C, Baqui $\mathrm{AH}$, Black R. Progress and barriers for the control of diarrheal disease. Lancet. 2010;376:63-7.

35. Bachewar N, Thawani V, Gharpure K. Are ORS brands in India using the name of WHO judiciously? Indian J Pharmacol. 2006;38:439-41.

36. Kumar GS, Kar SS, Jain A. Health and environmental sanitation in India: Issues for prioritizing control strategies. Indian J Occup Environ Med. 2011;15:93-6.

\section{$\overline{\text { CLIPPINGS }}$}

\section{Seasonal fluctuations in T4 and TSH measurement in NBS program (Int J Neonatal Screen. 2021;7:8)}

Newborn screening for hypothyroidism is universally practiced in most developed countries. This study from New York, USA evaluated the effect of seasonal changes in kits for NBS used on 2.4 million babies between 2008 to 2017 . The measurement of T4 and TSH was based on fluroimmunoassay principle in dried blood spots. A higher level of TSH and T4 with higher false positive rate was seen in the colder months, indicating the effect of seasonal temperature variations in these kits. However, the number of confirmed hypothyroid cases remained the same irrespective of the season. They suggested the need to be aware of these fluctuations to optimize the recall rates in screen positive babies.

\section{Prediction of childhood obesity from BMI acceleration patterns (J Pediatr. Feb 2021. Epub ahead of print)}

This study from Israel analyzed BMI acceleration patterns among 417,915 adolescents. Electronic health records of children between 2002 to 2018 were retrieved to devise a model to predict obesity (BMI $>95^{\text {th }}$ centile). The model recorded the greatest acceleration in BMI at 2-4 years of age in obese adolescents and accurately predicted obesity at 5-6 years of age (AUC 0.803). Thus, anthropometric parameters during early childhood were concluded as important predictors of obesity at a later age.

Kumar ANGADI drkumarangadi@gmail.com 